\title{
PENGARUH METODE PEMBELAJARAN DAN GAYA KOGNITIF TERHADAP PEMAHAMAN PHYSICAL SCIENCE PADA ANAK KELOMPOK B TAMAN KANAK-KANAK DI KOTA PADANG
}

\author{
Meilina*, Hapidin**, Karnadi*** \\ Surel:meilina1515@gmail.com
}

\begin{abstract}
The objective of this research is to know impact of learning method and cognitive style against physical science comprehension. This research using experimental method of $2 \times 2$ factorial design. Research result indicated that : 1)Physical science comprehension of children thought by discovery learning method is higher compared to method of project base learning, 2)There is interaction impact between learning method and cognitive style against physical science comprehension, 3)Physical science comprehension of children's independent field cognitive style had been given higher learning method discovery compared to method of project base learning, 4)Physical science comprehension of children who has dependent field learning method discovery is lower compared to method of project base learning.
\end{abstract}

Keyword: Method, Style, Comprehension

\begin{abstract}
ABSTRAK
Tujuan penelitian ini adalah untuk mengetahui pengaruh metode pembelajaran dan gaya kognitif terhadap pemahaman physical science. Penelitian ini menggunakan metode eksperimen desain factorial 2 x 2. Hasil penelitian menunjukkan bahwa: 1)Pemahaman physical science anak yang diajarkan melalui metode discovery lebih tinggi dibandingkan dengan metode project, 2)Terdapat pengaruh interaksi antara metode pembelajaran dan gaya kognitif terhadap pemahaman physical science 3)Pemahaman physical science anak gaya kognitif field independent diberikan metode discovery lebih tinggi dibandingkan dengan metode project, 4)Pemahaman physical science anak gaya kognitif field dependent diberikan metode discovery lebih rendah dibandingkan dengan metode project.
\end{abstract}

Kata Kunci: Metode, Pemahaman

*Universitas Negeri Jakarta

Accepted: 3 Desember 2018

**Universitas Negeri Jakarta

Published: 18 Desember 2018

****Universitas Negeri Jakarta 


\section{PENDAHULAN}

Pembelajaran sains bagi anak usia dini ditujukan agar anak memiliki kemampuan memecahkan masalah, memiliki sikap ilmiah, dan mengasah kepekaan panca indera dalam bereksplorasi untuk memahami lingkungan sekitar. Salah satu konsep pembelajaran sains untuk anak usia dini yaitu physical science.

Physical science untuk anak usia dini melibatkan eksplorasi langsung terhadap suatu objek, material, dan peristiwa dari benda mati yang ada disekitar anak dan terintegrasi dalam kehidupan sehari-hari. Fokus tingkatan pengeksplorasian mereka dari struktur yang dibuat oleh beberapa material, benda-benda yang bergerak, air, dan cairan lainnya, bayangan, cahaya, dan suara. Pada anak usia dini fenomena yang diajarkan sedikit berbeda, dikemas secara menarik serta menantang untuk dieksplorasi.

Penelitian yang dilakukan oleh Levy (2012) dengan judul Young Children's Learning of Water Physics by Constructing Working Systems, menyatakan anak usia dini yang berusia 5-6 tahun dapat memahami physical science tentang sifat air melaui sistem kerja yang terkonstruktif. Pernyataan tersebut menegaskan bahwa melalui sistem kerja yang terkonstruktif maka anak dapat memahami konten pembelajaran physical science. Disinilah pentingnya peran guru dalam merancang suatu kegiatan sains yang membuat anak dapat bereksplorasi untuk mendapatkan pemahaman physical science.
Penelitian yang dilakukan oleh Sac kes (2010) dengan judul The Influence of Early Science Experience in Kindergarten on Children's Immediate and Later Science Achievement: Evidence From the Early Childhood Longitudinal Study, hasil dari penelitian ini menyatakan anak yang mendapatkan pengalaman belajar sains di TK, maka anak memahami tentang konsep dan content sains, yang nantinya memberikan pengaruh terhadap pencapaian hasil belajar anak ketika menempuh pendidikan selanjutnya.

Hasil penelitian yang ditulis oleh Brostrom (2015) dengan judul Science in Early Childhood Education menjelaskan bahwa permasalahan yang terjadi di prasekolah dalam pembelajaran sains, adalah kemampuan seorang guru yang belum optimal menggunakan suatu metode pengajaran ilmiah sehingga anak tidak dapat mengkonstruksi pengetahuannya dalam memahami fenomena sains.

Hasil survey Programme for International Studens Assesment (PISA) (2015), menunjukkan pencapaian siswa Indonesia dalam bidang sains, berada diperingkat 62 dari 69 negara yang dievaluasi. Pencapaian prestasi sains yang diperoleh siswa Indonesia tidak berbeda jauh dengan hasil tes dan survey PISA terdahulu pada tahun 2012 yang juga berada pada kelompok penguasaan materi yang rendah. Dengan kata lain rendahnya penguasaan konsep dan konten dalam pembelajaran sains menjadi faktor yang 
utama dalam mencapai prestasi sains di tingkat international.

Selanjutnya hasil observasi dan wawancara yang peneliti lakukan dengan guru di kelompok B taman kanak-kanak Adhyaksa XXVI kota Padang dengan subjek 60 anak diperoleh informasi bahwa pemahaman sains fisik anak masih rendah. Hal ini dibuktikan dengan fakta sebagai berikut: 1) sebagian besar anak belum dapat mengklasifikasi benda berdasarkan ciri-ciri benda, 2) sebagian besar anak masih belum bisa mencontohkan perubahan wujud benda, 3) masih banyak anak yang belum dapat menjelaskan pergerakkan aliran air, 4) masih banyak anak yang belum dapat membandingkan benda yang tenggelam dan merapung.

Berdasarkan penjelasan dari beberapa hasil analisis penelitian sebelumnya, didukung dengan hasil PISA dan hasil observasi diatas, terlihat rendahnya pemahaman physical science anak usia dini. Hal ini dipengaruhi oleh beberapa faktor yang meliputi guru tidak menguasai metode yang efektif untuk mengajarkan konsep dan konten sains yang sesuai dengan standar dan tahap perkembangan kognitif anak, selain itu media yang digunakan, frekuensi dan durasi pengajaran sains oleh guru.

Anak usia 5-6 tahun dalam memahami konsep sains fisik menurut Dodea (Departement of Defense Education Activity), standar physical science anak dapat menunjukkan pemahaman terhadap objek dan dapat menjelaskan ciri-ciri yang diamati. Pemahaman physical science memberikan pengaruh yang positif terutama dalam aspek perkembangan kognitif anak diantaranya anak mampu berpikir kritis, mampu menyelesaikan masalah, dan mampu mengembangkan keterampilan ilmiah.

Tinggi rendahnya pemahaman physical science dipengaruhi oleh faktor internal dan eksternal. Salah satu faktor internal anak yang penting diperhatikan oleh guru adalah gaya kognitif. Gaya kognitif berhubungan dengan cara anak menerima dan memproses suatu informasi. Gaya kognitif anak berpengaruh terkait dalam cara menerima dan menyikapi materi pelajaran. Hal ini dikarenakan apakah dalam berpikir anak tersebut cenderung memiliki kemandirian berpikir (field independent) atau ketergantungan berpikir (field dependent).

Dalam jurnal yang berjudul Analysis of Student Teacher Cognitive Styles Interaction: An Approach to Understanding Learner Performance, yang ditulis oleh Sellah (2017), dkk, menyatakan gaya kognitif dipengaruhi oleh interaksi guru dengan siswa didalam proses pembelajaran, misalnya pendekatan, strategi dan model yang digunakan oleh guru. Hal ini menunjukkan bahwa pendidik harus dapat mengusai cara penyajian materi didalam kelas, karena setiap anak ketika belajar memiliki gaya kognitif yang berbeda.

Faktor eksternal yang berpengaruh terhadap pemahaman physical science adalah metode pembelajaran yang diterapkan oleh guru dalam proses pembelajaran. 
Dalam memilih metode pembelajaran, guru harus memahami dari materi yang akan disampaikan untuk anak usia dini. Pemilihan metode yang tepat akan dapat membantu anak memahami konsep sains fisik.

Agar anak mendapatkan pemahaman physical science yang lebih baik, pendidik harus mampu mendesain pembelajaran yang memberikan kesempatan kepada anak untuk mengkonstruksi sendiri pengetahuannya dengan berbagai kegiatan yang sifatnya eksploratif dan manipulative. Hal penting yang perlu diperhatikan oleh guru agar anak dapat memahami konsep sains fisik adalah penggunaan metode pembelajaran yang berorientasi pada siswa (student centre). Berkenaan dengan metode pembelajaran yang dibutuhkan diatas, maka peneliti memilih dua jenis metode pembelajaran yang diduga dapat memberikan pengaruh terhadap pemahaman sains fisik anak di TK, yaitu metode discovery learning. dan metode project base learning.

Penelitian dengan judul Preeschool Science Environment: What Is Available in A Preschool Classrom, yang ditulis oleh Tu (2006), penelitian ini meneliti tentang lingkungan sains di pendidikan anak usia dini. Hasil dari penelitian ini menunjukkan selain tersedianya kelengkapan alat-alat dan bahan-bahan untuk pembelajaran sains, metode discovery learning merupakan unsur yang penting dalam pembelajaran sains dikelas. Berdasarkan dari penelitian ini metode discovery learning membuat anak aktif dalam kegiatan sains, melatih keterampilan scientifiq inquiry, dan anak akan bebas bereksplorasi untuk menemukan suatu jawaban dari stimulus yang diberikan.

Sejalan dengan penelitian diatas, didalam jurnal yang ditulis oleh Sari (2016), dengan judul Penerapan Metode Discovery Berbantuan Media Alam untuk Meningkatkan Kemampuan Kognitif, hasil dari penelitian ini menyatakan penerapan metode discovery berbantuan media alam dapat meningkatkan kemampuan kognitif anak dalam lingkup kemampuan memecahkan masalah dan berpikir logis. Dari hasil penelitian ini dapat dijadikan sebagai bahan rujukan bahwa perkembangan kognitif anak usia dini dapat distimulasi melalui kegiatan sains di TK dengan menggunakan metode discovery learning.

Sementara itu penelitian yang ditulis oleh Eckhoff (2016), yang berjudul Partners in Inquiry: A Collaborative Life Science Investigation with Preservice Teachers and Kindergarten Students, menyatakan proyek kolaborasi yang dilakukan dilembaga pendidikan anak usia dini dalam pembelajaran sains dengan tema makhluk hidup dapat mengembangkan keterampilan berbasis inquiry di TK.

Berdasarkan dari beberapa hasil penelitian sebelumnya yang telah diuraikan diatas, belum berfokus pada pemahaman konsep sains fisik melalui metode pembelajaran discovery learning yang dikaitkan dengan faktor yang mempengaruhi anak dalam menerima dan memproses suatu informasi yaitu gaya kognitif. Oleh 
karena itu penelitian ini dipandang penting untuk dilakukan agar anak mendapatkan pemahaman physical science yang sesuai dengan standar pembelajaran sains untuk anak usia dini, dengan mempertimbangkan faktor internal dan eksternal. Penelitian ini akan mengkaji pengaruh metode pembelajaran dan gaya kognitif terhadap pemahaman physical science pada anak kelompok B di TK.

\section{METODE PENELITIAN}

Penelitian ini dilaksanakan dengan menggunakan metode eksperimen dengan desain factorial $2 \mathrm{x}$ 2 untuk membandingkan dua metode pembelajaran yaitu metode pembelajaran discovery learning dan metode pembelajaran project base learning dan variabel atribut yaitu gaya kognitif yang diklasifikasikan menjadi dua yakni gaya kognitif field independent dan gaya kognitif field dependent.

Teknik pengumpulan data yang dilakukan dalam penelitian ini menggunakan dua instrument yaitu data tentang pemahaman physical anak dengan menggunakan instrument non tes yang telah dibuat peneliti, berbentuk tes perbuatan dan wawancara dalam bentuk pertanyaan pada anak yang dilihat dari seberapa mampu anak menguasai materi yang telah diajarkan, setelah diuji kevaliditasannya oleh ahli dan data gaya kognitif dalam bentuk kuesioner yang telah dibuat oleh peneliti setelah diuji kevaliditasannya oleh ahli.

Teknik pengambilan sampel dilakukan dengan teknik multistage random sampling. Teknik analisis data dalam penelitian ini diuji dengan teknik analisis varians (ANAVA) dua jalur 2 $x$ 2. Agar pengujian hipotesis dapat dilaksanakan maka perlu dilakukan uji persyaratan analisis yakni uji normalitas dan uji homogenitas. uji normalitas dilakukan dengan Uji Lifefors dan uji homogenitas dilakukan dengan Uji Barlett. Pengujian selanjutnya dilakukan dengan menggunakan Uji Tukey.

\section{HASIL DAN PEMBAHASAN}

Setelah dilakukan analisis data dengan menggunakan analisis varians (ANAVA) dan dilanjukan dengan uji Tukey, maka pembahasan hasil penelitian akan terpusat pada empat hipotesis yang telah diuji kebenarannya sebagai berikut.

Pemahaman physical science pada kelompok anak yang diberikan metode pembelajaran discovery learning lebih tinggi dibandingkan dengan kelompok anak yang diberikan metode pembelajaran project base learning

Berdasarkan hasil perhitungan ANAVA bahwa $F_{\text {hitung }}=22,83>$ $\mathrm{F}_{\text {tabel }}=3,96$ pada taraf signifikan $\alpha=$ 0,05 dengan demikian $\mathrm{H}_{0}$ ditolak dan hipotesis alternatif $\mathrm{H}_{1}$ diterima, artinya hipotesis alternatif yang menyatakan bawa terdapat perbedaan pemahaman physical science antara kedua kelompok anak yang diberi perlakuan dua metode pembelajaran discovery learning dan project base learning secara keseluruhan terbukti signifikan. Perbedaan rata-rata skor pengetahuan pemahaman physical science anak yang 
Meilina: Pengaruh Metode Pembelajaran....

diberikan metode pembelajaran discovery learning $\overline{\mathrm{X}}=49,07$ lebih tinggi secara nyata dibandingkan kelompok anak yang diberikan metode pembelajaran project base learning $\overline{\mathrm{X}}=$ 46,27. Hasil yang didapat menunjukkan bahwa secara keseluruhan pemahaman physical science pada kelompok anak yang diberikan metode pembelajaran discovery learning lebih tinggi dibandingkan kelompok anak yang diberikan metode pembelajaran project base learning.

Berdasarkan perbedaan ini dapat dijelaskan bahwa metode pembelajaran discovery learning dikembangkan berdasarkan pandangan kognitif tentang pembelajaran dan prinsip-prinsip konstruktivis. Hasil penelitian yang dilakukan oleh Kistian et. all (2017), menjelaskan bahwa metode pembelajaran discovery learning berfokus pada anak dalam proses pembelajaran, dengan metode ini guru hanya bertindak sebagai mentor dan fasilitator dalam mengarahkan dan membanguan pengetahuan anak dengan memberikan masalah yang harus dipecahkan melalui langkah-langkah ilmiah, yang dimulai dengan stimulasi, membuat rumusan masalah, mengumpulkan data, memverivikasi data, dan mengeneralisasi. Melalui metode discovery learning anak berpartisipasi aktif dengan menemukan sendiri, menyelidiki sendiri, dengan mengikuti langkah-langkah penyelidikan ilmiah sehingga hasil yang diperoleh akan tahan lama dalam ingatan anak.

Menurut Bruner (2006), dalam melakukan kegiatan yang sifatnya menemukan jawaban atas permasalahan yang sedang dihadapi secara sendiri, maka akan lebih memudahkan dalam mengakses informasi didalam memori. Dalam hal ini dapat dipahami bahwa kegiatan pembelajaran yang dalam menemukan jawaban atas permasalahan yang sedang dihadapi dilakukan dengan cara penemuan maka akan lebih memudahkan dalam menghubungkan konsep pengetahuan yang sebelumnya telah diperoleh dengan konsep pengetahuan baru.

Metode pembelajaran project base learning melibatkan pastisipasi aktif dari anak dan juga guru. Vartainen (2008), mendefenisikan pembelajaran berbasis proyek (PjBL) yaitu program proyek yang difokuskan kepada hasil proyek dan motivasi belajar dari lingkungan secara berkelompok. Pembelajaran berbasis proyek mengutamakan kerjasama antara individu untuk menyelesaikan proyek. Aktivitas bermain yang dilaksanakan dengan kelompok memberikan kesempatan bagi anak untuk memperoleh keterampilan sosial. Metode pembelajaran project base learning dalam pelaksanaanya seringkali menghabiskan banyak waktu dan membuat kesulitan dalam mencari ide-ide kreatif untuk merancang sebuah aktifitas dan terkadang sulit memotivasi anak untuk belajar.

Terdapat interaksi antara metode pembelajaran dengan gaya kognitif terhadap pemahaman physical science.

Hasil perhitungan ANAVA AxB menunjukkan bahwa $F_{\text {hitung }}=45,04$ > $\mathrm{F}_{\text {tabel }}=3,96$ pada taraf signifikan $\alpha=$ 
0,05 dengan demikian $\mathrm{H}_{0}$ ditolak dan $\mathrm{H}_{1}$ diterima. Dengan demikian dapat diambil keputusan bahwa terdapat pengaruh interaksi yang signifikan antara metode pembelajaran, dan gaya kognitif terhadap pemahaman physical science. Signifikasi interaksi ini akan berpengaruh pada bentuk interaksi yang terjadi, artinya pengaruh interaksi akan mempunyai makna penting jika dilakukan pengujian setiap tingkat perlakuan. Pengaruh interaksi ditunjukkan oleh hasil pengujian hipotesis seperti gambar berikut.

Dalam gambar tersebut terlihat bahwa pemahaman physical science kelompok anak yang memiliki gaya kognitif field independent diberikan metode pembelajaran discovery learning lebih tinggi dibandingkan kelompok anak yang diberikan metode pembelajaran project base learning. Sementara itu anak yang memiliki gaya kognitif field dependent diberikan metode pembelajaran discovery learning lebih rendah dibandingkan kelompok anak yang diberikan metode pembelajaran project base learning. Hal ini menunjukkan bahwa penggunaan metode pembelajaran berhubungan dengan karakteristik anak. Metode pembelajaran menurut Moeslihatoen (2004), pada dasarnya adalah suatu cara yang digunakan oleh guru dalam proses pembelajaran, untuk mencapai tujuan pembelajaran yang telah direncanakan sebelumnya. Keberhasilan penggunaan metode pembelajaran juga ditentukan oleh bagaimana anak dapat menerima jalannya proses pembelejaran sesuai dengan gaya kognitif yang dimilikinya. Menurut Keefe (1987) gaya kognitif

merupakan bagian dari gaya belajar yang menggambarkan perilaku yang tetap dalam diri seseorang dalam menerima, memikirkan, memecahkan masalah, maupun dalam menyimpan informasi.

Dengan karakteristik dan gaya kognitif anak yang berbeda-beda, pemilihan metode pembelajaran secara tepat sesuai dengan karakteristik dan gaya kognitif anak merupakan salah satu bagian penting yang menunjang keberhasilan dalam pembelajaran. Dari temuan yang diperoleh pada penelitian ini, dapat disimpulkan bahwa terdapat interaksi antara metode pembelajaran dan gaya kognitif terhadap pemahaman physical science.

Berdasarkan hasil perhitungan analisis varians tahap lanjut dengan Uji Tukey untuk membandingkan pemahaman physical science kelompok yang memiliki gaya kognitif field independent diberikan metode pembelajaran discovery learning dan metode pembelajaran project base learning diperoleh nilai $\mathrm{Q}_{\text {hitung }}=$ $18,55>Q_{\text {tabel }}=2,95$ pada taraf signifikan $\alpha=0,05$ dengan demikian $\mathrm{H}_{0}$ ditolak dan $\mathrm{H}_{1}$ diterima. Selain itu, skor rata-rata anak yang memiliki gaya kognitif field independent yang diberi metode pembelajaran discovery learning $\quad \bar{X}=56,25$ lebih tinggi dibandingkan yang diberikan metode pembelajaran project base learning $\overline{\mathrm{X}}=$ 44,3 .

Hasil uji hipotesis ketiga
membuktikan $\mathrm{H}_{1}$ diterima yang
menyatakan bahwa kelompok anak
yang memiliki gaya kognitif field
independent diberikan metode


pembelajaran discovery learning lebih tinggi dibandingkan kelompok anak yang diberikan metode pembelajaran project base learning. Dikatakan bahwa kedua bentuk metode pembelajaran ini mempunyai tujuan yang sama dalam meningkatkan pemahaman physical science, tetapi memiliki perbedaan dalam pelaksanaannya. Pelaksanaan metode discovery learning berdasarkan pendapat Balim (2009) lebih mengutamakan keaktifan anak dalam menemukan pengetahuan tentang suatu konsep yang harus dicapai dengan mengikuti langkah-langkah penyelidikan ilmiah.

Metode pembelajaran discovery learning melibatkan peserta didik aktif untuk meningkatkan penalaran, kemampuan berpikir secara bebas, dan melatih keterampilan kognitif anak dengan cara menemukan dan memecahkan masalah yang ditemui menggunakan pengetahuan yang dimiliki sebelumnya, sehingga menghasilkan pengetahuan baru yang benar-benar bermakna bagi dirinya. Winkel (1996), menyatakan anak yang memiliki gaya kognitif field independent dikelompokkan sebagai orang yang memiliki kemampuan analisis, mampu menguraikan sedetail mungkin suatu konteks, mempunyai kemampuan mengingat, memiliki ketilitian yang tinggi, motivasi dalam diri, dan mampu memecahkan masalah. Dari uraian diatas dapat direkomendasikan bahwa metode discovery learning lebih efektif digunakan bagi anak yang memiliki gaya kognitif field independent untuk meningkatkan pemahaman physical science.

Berdasarkan hasil perhitungan analisis varians tahap lanjut dengan uji Tukey untuk membandingkan pemahaman physical science kelompok anak yang memiliki gaya kognitif field dependent yang diberikan metode pembelajaran discovery learning dan kelompok anak yang diberikan metode pembelajaran project base learning diperoleh $Q_{\text {hitung }}=-6,11<Q_{\text {tabel }}=$ 2,95 atau $Q_{\text {hitung }}<Q_{\text {tabel }}$ pada taraf signifikan $\alpha=0,05$, dengan demikian $\mathrm{H}_{0}$ ditolak dan $\mathrm{H}_{1}$ diterima. Skor ratarata kelompok anak yang memiliki gaya kognitif field dependent diberikan metode pembelajaran discovery learning $\quad \bar{X}=45,5$ lebih rendah dibandingkan dengan menggunakan metode pembelajaran project base learning $\overline{\mathrm{X}}=48,25$.

Hasil uji hipotesis keempat diterima membuktikan bahwa kelompok anak yang memiliki gaya kognitif field dependent diberikan metode pembelajaran discovery learning lebih rendah dibandingkan kelompok yang diberikan metode pembelajaran project base learning .

Gaya kognitif field dependent menurut Witkin (2006) memiliki ciriciri seperti: kemampuan analisis rendah, cenderung berpikir global, berorientasi sosial, mempunyai kemampuan mengingat atau ketelitian rendah, memiliki motivasi ekstrinsik, dan kurang mampu memecahkan masalah secara spersifik. Karakteristik semacam ini bila diberikan metode pembelajaran discovery learning yang lebih mengutamakan dalam 
menemukan suatu konsep atau Terdapat pengaruh interaksi antara memecahkah suatu masalah yang metode pembelajaran discovery diberikan, kurang efektif untuk learning dan metode pembelajaran diterapkan.

Anak yang memiliki gaya project base learning dan gaya kognitif kognitif field dependent lebih senang belajar dengan cara berkelompok. Oleh karena itu metode pembelajaran project base learning direkomendasikan bagi anak yang memiliki gaya kognitif field dependent untuk meningkatkan pemahaman physical science. Pernyataan ini didiukung oleh hasil penelitian yang dilakukan oleh Vartiainen (2008), pembelajaran berbasis proyek mengutamakan kerjasama antara individu untuk menyelesaikan proyek. Dari penjelasan yang telah dikemukan dapat dikatakan bahwa pemahaman physical science untuk anak yang memiliki gaya kognitif field dependent dapat ditingkatkan dengan menggunakan metode project base learning.

\section{SIMPULAN}

Berdasarkan hasil pemaparan pada bagian hasil dan pembahasan, maka dapat dikemukakan beberapa kesimpulan sebagai berikut:

Secara umum pemahaman physical science anak yang diajarkan dengan menggunakan metode pembelajaran discovery learning memiliki pengaruh yang lebih tinggi dari metode pembelajaran project base learning. Hal ini berdasarkan perhitungan ANAVA dua jalur yang menunjukkan bahwa $\mathrm{F}_{\text {hitung }}=22,83>\mathrm{F}_{\text {tabel }}=3,96$ pada taraf signifikan $\alpha=0,05$ dengan demikian $\mathrm{H}_{0}$ ditolak dan hipotesis alternatif $\mathrm{H}_{1}$ diterima, terhadap pemahaman physical science, hal ini berdasarkan perhitungan ANAVA dua jalur yang menunjukkan bahwa H0 ditolak berdasarkan nilai $\mathrm{F}_{\text {hitung }}=45,04>\mathrm{F}_{\text {tabel }}=3,96$ pada taraf signifikan $\alpha=0,05$.

Pemahaman physical science anak yang memiliki gaya kognitif field independent yang diberikan metode pembelajaran discovery learning lebih tinggi nilainya dibandingkan dengan anak yang diberikan metode pembelajaran project base learning. Hal ini berdasarkan perhitungan analisis varians tahap lanjut dengan Uji Tukey diperoleh $\mathrm{Q}_{\text {hitung }}=18,55>$ $\mathrm{Q}_{\text {tabel }}=2,95$ pada taraf signifikan $\alpha=$ 0,05 dengan demikian $\mathrm{H}_{0}$ ditolak dan $\mathrm{H}_{1}$ diterima.

Pemahaman physical science anak yang memiliki gaya kognitif field dependent diberikan metode discovery learning lebih rendah dibandingkan anak yang diberikan metode pembelajaran project base learning. Hal ini berdasarkan perhitungan analisis varians tahap lanjt dengan Uji Tukey diperoleh nilai $\mathrm{Q}_{\text {hitung }}=-6,11<$ $Q_{\text {tabel }}=2,95$ dengan demikian $\mathrm{H}_{0}$ ditolak dan $\mathrm{H}_{1}$ diterima.

\section{DAFTAR RUJUKAN}

Balim, Ali Gunay. 2009. The Effect of Discovery Learning on Students Succes and Inquiry Leaning Skills. Eurasian 
Meilina: Pengaruh Metode Pembelajaran....

Journal of Educational

Research.

Brunner, Jarome S. 2006. E-Book: In Search of Pedagogy Volume I

The Selected works of Jarome $S$. Bruner. Londonand New York: Rouledge.

Departemen of Defense Education Activity, College and Career Ready Standards For Science.

Eckhoff, Angela. 2016. Partners in Inquiry: A Collaborative Life Science Investigation with Preservice Teachers and Kindergarten Students. Early Childhood Educ J, DOI 10.1007/s 10643-015-0769-3.

Keefe, James W. 1987. Learning Style Theory and Practice. Virgina: NASSP Association Driven.

Kistian, Agus. 2017. The Effect of Discovery Learning Method on The Math Learning of The $V$ SDN 18 of Banda Aceh. Indonesia, British Journal of Education, Vol: 5, No. 11.

Levy T, Sharona T. 2012. Young

Children's Learning of Water Physics by Constructing Working Systems. Int $\mathbf{J}$ Technol Des Educ. PISA 2015 Result

R, Moeslihatoen. 2004. Metode Pengajaran di Taman KanakKanak. Jakarta: PT. Rineka Cipta.

Sac,kes, Mesut, et.al. 2010. The Influence of Early Science Experience in Kindergarten on Children's Immediate and Later Science Achievement: Evidence From the Early
Childhood Longitudinal Study. Journal Of Research In Science Teaching, Vol:48 No.2.

Sari, Desak Komang Setia Purnama. 2016.Penerapan Metode Discovery Berbantuan Media Alam untuk Meningkatkan Kemampuan Kognitif. eJournal Pendidikan Anak Usia Dini Universitas Pendidikan Ganesha, Vol: 4 No. 3.

Sellah, Lusweti, et.al. 2017. Analysis of Student Teacher Cognitive Styles Interaction: An Approach to Understanding Learner Performance. Journal of Education and Practice, Vol: 8 No.14.

Slavin, Robert E. 2008. Pskilogi Pendidikan Teori dan Praktik. Jakarta: PT Indeks.

Stig, Brostrom. 2015. Science in Early Childhood Education, Journal of Education and Human Development, Vol. 4, No. 2(1).

Tu, Tsunghui. 2006. Preschool Science Enviroment: What Is Available in a Preschool Room. Early Childhood Education, Vol: 3, No. 4.

Vartiainen, Tero. Moral Conflicts in Project-Base Learning in ISD, Technology \& People. Vol. 23 ISS 3

Witkin, A.H. 2006. Field Dependent and Field Independent Cognitive Styles and Their Educational Implication. New York: American Educational Research Journal. 